HELMINTHOLOGIA, 57, 4: 322 - 334, 2020

\title{
Clinical-parasitological screening for respiratory capillariosis in cats in urban environments
}

\author{
P. STEPANOVIĆ ${ }^{1, *}$, D. DESPOTOVIĆ ${ }^{2}$, S. DIMITRIJEVIĆ ${ }^{3}$, T. ILIĆ$^{3}$ \\ 'Department for equine, small animal, poultry and wild animal diseases, University of Belgrade, Faculty of Veterinary Medicine, \\ Bul. Oslobodjenja 18,11000 Beograd, Serbia, E-mail: pedja@vet.bg.ac.rs, prestepanovic@gmail.com; ${ }^{2 P I}$ Veterinary Institute \\ of the Republic of Srpska "Dr. Vaso Butozan" 78000 Banja Luka, Republic of Srpska, E-mail: darkodespotovicb/@gmail.com; \\ ${ }^{3}$ Department for Parasitology, University of Belgrade, Faculty of Veterinary Medicine, Bul. Oslobodjenja 18, 11000 Beograd, Serbia, \\ E-mail: sanda@vet.bg.ac.rs, tamara@vet.bg.ac.rs
}

Article info

Received April 3, 2020

Accepted July 24, 2020

\section{Summary}

Respiratory capillariosis is a widely distributed zoonotic parasitic disease caused by the nematode Capillaria aerophila (Trichocephalida, Trichuridae) that commonly infects wild carnivores but also cats and dogs. This retrospective study aims to describe cases of respiratory capillariosis in cats from the city of Belgrade, Serbia. Between 2015 and 2019, a total of 155 pet cats with or without respiratory symptoms were submitted to physical examination and parasitological examination of the feces. All cats lived indoor but had free access to outdoor. In suburban settlements, wild carnivores commonly share their living environments with owned cats and dogs. It can be assumed that more intense urbanization spreading into the natural habitats of will carnivores creates the opportunity for closer and more frequent contacts between the population of cats and feral carnivores which might increase the risk of feline contamination. The findings confirm the existence of capillaries in cats in urban areas of the city of Belgrade, contribute to a better understanding of the epidemiology of this nematode and warn that, because of close contacts between cats of pets and humans, capillaries can cause human infection.

Keywords: Capillaria aerophila; cat; coprology; physical examination; Belgrade

\section{Introduction}

Respiratory capillariosis caused by the nematode Capillaria aerophila (Trichocephalida, Trichuridae) is a parasitic disease common in wild carnivores including foxes (Sreter et al., 2003; Lalošević et al., 2013; Čabrilo et al., 2018), coyotes (Gompper et al, 2003), wolves (Pence \& Bryant, 2002), raccoons (Schuster et al., 2001) and bears (Crum et al., 1978; Paoletti et al., 2017). The nematode may also infect dogs (Traversa et al., 2009), cats (Madeira de Carvalho et al., 2009), and sporadically humans (Lalošević et al., 2008; Di Cesare et al., 2012).

Capillaria aerophila has a worldwide distribution and is considered as the second most common respiratory helminth of domestic cats in the Northern Hemisphere after Aelurostrongylus abstrusus (Knaus et al., 2015). Adult stages of the parasite live on the surface of bronchioles, bronchi, and trachea, where they are completely or partly fixated to the mucosa, causing injury to the epithelium and lung parenchyma. Although less frequently, they can also infest the nasal mucosa and nasal and frontal sinuses (Barrs et al., 2000).

Capillaria aerophila infection is usually subclinical and reported sporadically in cats. However, in the past three decades, the parasite has been increasingly detected in cats in Europe (Traversa et al., 2010), Asia (Matayoshi et al., 1996; Bowman et al., 2008), Australia (Milstein \& Goldsmid, 1997), New Zealand (Langham \& Charleston, 1990), North Africa (Kohart et al., 2014) and North and South America (Echeverry et al., 2012).

Knowledge of epidemiological data (e.g. range of hosts and geo-

\footnotetext{
* - corresponding author
} 
graphic distribution) of C. aerophila in Europe is fragmentary, thus at the moment it is difficult to assess to what degree this parasite may be spreading or what influence global warming or other factors may have on the current distribution. Indeed, although climate changes seem to play a key role in the epidemiological variations for pet heart-worms and lungworms, other possible factors can not be ruled out (Traversa et al., 2010). In Europe, C. aerophila is widely distributed as supported by the published feline case reports in Hungary (Capári et al., 2013; Rehbein et al., 2014), Belgium (Thienpoint et al., 1981), France (Elhamiani Khatat et al., 2016), Germany (Krone et al., 2008), Serbia (llić et al., 2009), Greece (Haralampides, 1978), Italy (Di Cesare et al., 2010; Spada et al., 2013), Albania (Knaus et al., 2014), Portugal (Waap et al., 2014), Romania (Mircean et al., 2010), Austria, Bulgaria, Latvia and Lithuania (Rehbein et al., 2014. Recently, different genetic haplotypes of $C$. aerophila have been shown to coexist in foxes, martens, cats, and dogs in European countries, confirming a common pattern of transmission of this parasite between wild animals and pets (Di Cesare et al., 2014).

In feline medicine, respiratory parasitic infections represent a particular challenge for clinicians due to a large number of conditions with similar clinical manifestations. Knowledge of the prevalence and clinical expression of the disease in cats such as malaise, cough, sneezing, mucopurulent nasal discharge, and "air hunger" should encourage the veterinarian to consider pulmonary capillariosis in the differential diagnosis of these clinical manifestations (Traversa et al., 2010). Furthermore, given the prevalence and zoonotic potential of $C$. aerophila, it is recommended to include it in the differential diagnosis of cardio-respiratory diseases in dogs and cats.

Therefore, this paper aims to determine the prevalence of $C$. aerophila infection in cats through the parasitological examination of the feces in the city of Belgrade, Serbia, and its suburban settlements and to describe the clinical signs and complains associated with this infection.

\section{Material and Methods}

\section{Research period and area}

This retrospective study is based on the record protocols of the University Clinic for Small Animals, and the Department of Parasitology, Faculty of Veterinary Medicine, University of Belgrade (Serbia) which included all cats that had any respiratory problems in the period $2015-2019$ (155). The cats enrolled were from the city of Belgrade including its suburban settlements $\left(44^{\circ} 49^{\prime} \mathrm{NG}\right.$ and $20^{\circ} 27^{\prime}$ IGD). The city covers an area of 322,268 ha, of which 35,996 belongs to the inner city area.

\section{Studied population}

A total of 155 files of pet cats were searched. Out of the total number of examined cats, 61 were male and 94 female. The cats were $2-9$ years old. From the files, we selected cats that live indoors but also have free access from the outside, including nearby parks and forests.

\section{Clinical examination}

For each cat, the following information was recorded including vaccination status, clinical difficulties observed by the owner especially respiratory symptoms, the duration of symptoms, previous consultation for the same difficulties, previous treatments, and the evolution with previous treatments. Each cat was then submitted to a physical examination which involved auscultation, and thermometry. Also, we found five cats with serious respiratory problems who have complete blood cell count, chest $x$-rays, and only for the one dead cat also cytology from the tracheobronchial lavage. Necropsy was performed on one deceased cat. After the diagnosis was made and the degree of infection was determined, antiparasitics were recommended, and owners were advised to treat cats twice at intervals of 21 days.

\section{Parasitological examination of the feces}

The fecal samples were examined using the standard procedure of gravitational flotation with a saturated aqueous solution of $\mathrm{NaCl}$ (specific weight 1,200 at $20^{\circ} \mathrm{C}$ ) and the saturated aqueous solution of ZnSO4 (specific weight 1,350 at $20^{\circ} \mathrm{C}$ ) (Sloss et al., 1994). Using light microscopy, C. aerophila barrel-like eggs (length 74,50 \pm $1,50 \mu \mathrm{m}$, width $32.45 \pm 3.40 \mu \mathrm{m}$ ) were detected, with the asymmetry of bipolar plugs and walls with a network of anastomosing ridges (Traversa et al., 2011). The microscopical identification of other fecal endoparasites (Isospora spp., Toxocara mystax, Toxascaris leonina, Ancylostomatidae) was also performed at the same time, using qualitative methods of coprological diagnostic with the concentration of parasitic elements. By way of macroscopic feces examination, the proglottids of Dipylidium caninum were found, and after mechanical disintegration, the eggs of this cestode microscopically were found as well.

Quantification of the obtained results was made using the McMaster method (Kochanowski et al., 2013) and less than 50 eggs/g was diagnosed in the samples. Since the threshold of the method is 50 eggs/g, the degree of infection was determined approximately and helminth eggs were calculated according to the semi-quantitative fecal egg count (FEC) scale (Pittman et al., 2010). Using this scale, eggs can be calculated in $5-10 \mathrm{~g}$ of a fecal sample for an approximate determination of the three levels of the infection degree - low: $1-10(+)$, medium: $11-49(++)$ and high: $\geq 50(+++)$ of eggs calculated per a covering). The method semi-quantitative FEC is based on the principle of the fecal gravitation flotation. It is necessary to examine the whole fecal suspension in two microscopic slides and make the assessment of the egg count after that.

\section{Necropsy in one cat}

During the parasitological dissection of the respiratory tract, the trachea was isolated with the larynx until the bifurcation, was opened full length along the front and observed under the binocu- 


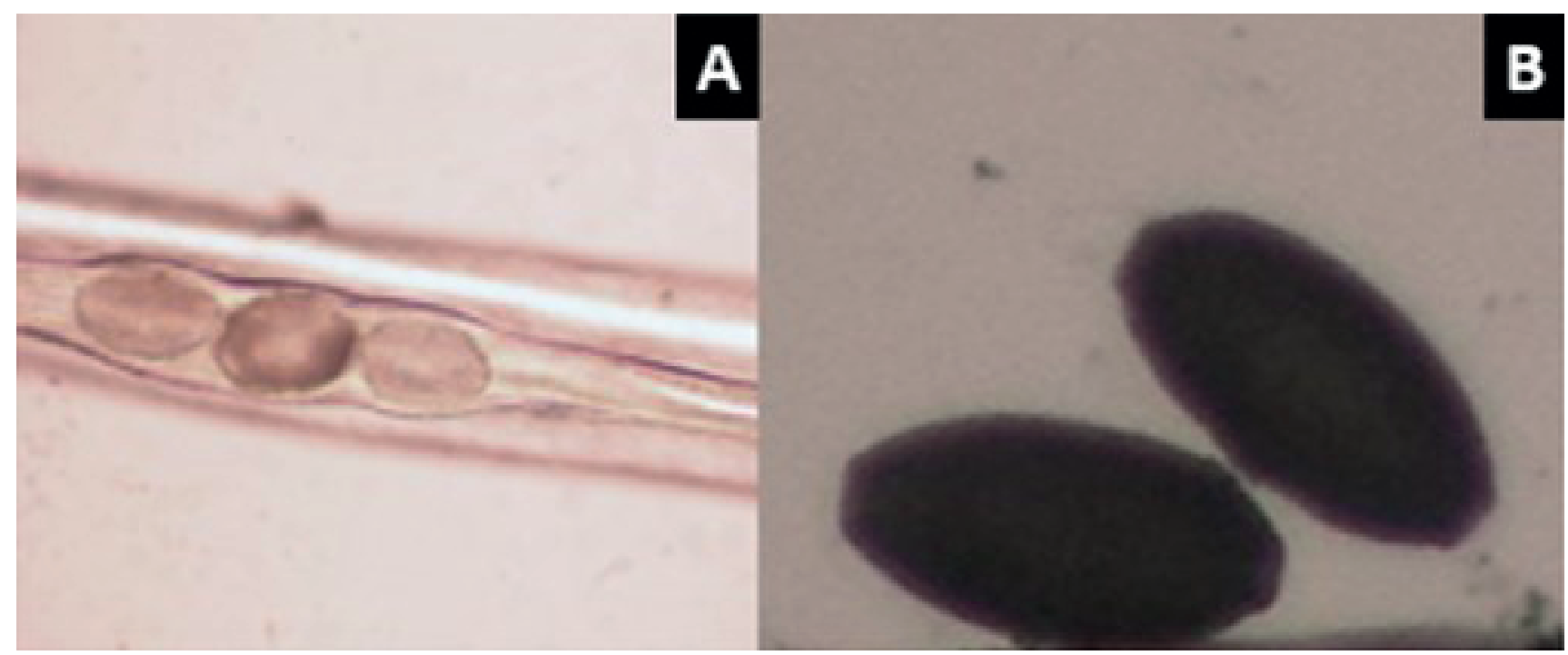

Fig. 1. Necropsy in one cat, light microscopy. A) Female C. aerophila with eggs embedded in the remnant uterus in the trachea of a cat, native preparation (100x magnification); B) Eggs of $C$. aerophila detected in microscopic examination of the tracheal lavage, native preparation (400x magnification)

lar magnifying glass, at a 50 times magnification. The macroscopical examination of samples from the trachea, bronchi, and lungs was also performed. We don't find a need for histologic evaluation in this case. Also, the tracheal lavage was cytologically evaluated. A sample of the pulmonary parenchyma $(25 \mathrm{~g})$ was examined by the Baerman technique. The material was examined fresh, after which adult capillaries were identified and then preserved in $30 \%$ ethyl alcohol.

\section{Morphological identification of parasites from the necropsy} Morphological identification of the collected parasites was performed at the Laboratory for Parasitology at the Department of Parasitology at the Faculty of Veterinary Medicine, University of Belgrade. After recovering, the parasite samples were washed in phosphate buffer saline (PBS), and clearing the nematodes lactophenol solution was used. Identification of nematodes was carried out by using a stereomicroscope (Carl Zeiss, Jena) and the nematodes were classified into species according to the standard taxonomic key (Anderson et al., 2009). Based on the diagnosed trichurid-type eggs and adult forms of the parasite, the finding of C. aerophila nematode was confirmed.

\section{Treatment}

The cats hospitalized at the Small Animal Clinic at the Faculty of Veterinary Medicine, University of Belgrade, received mostly fluid therapy, amoxicillin with clavulanic acid $(8.75 \mathrm{mg} / \mathrm{kg} / 24 \mathrm{~h} / \mathrm{SC} /$ divided into 2 or 3 doses), prednisolone ( $0.5 \mathrm{mg} / \mathrm{kg} \mathrm{PO} / 24 \mathrm{~h}$ ), fenbendazole (50 mg/kg PO/24h), theophylline (1.4 mg/kg PO/12h) and nebulization therapy in animal cages. Serious cases were managed in the intensive care unit.

Cats that had already been treated in other clinics and that had febrile and respiratory problems were hospitalized. Fenbendazole was given to all cats with respiratory symptoms in whom the presence of $C$. aerophila and other endoparasites was determined

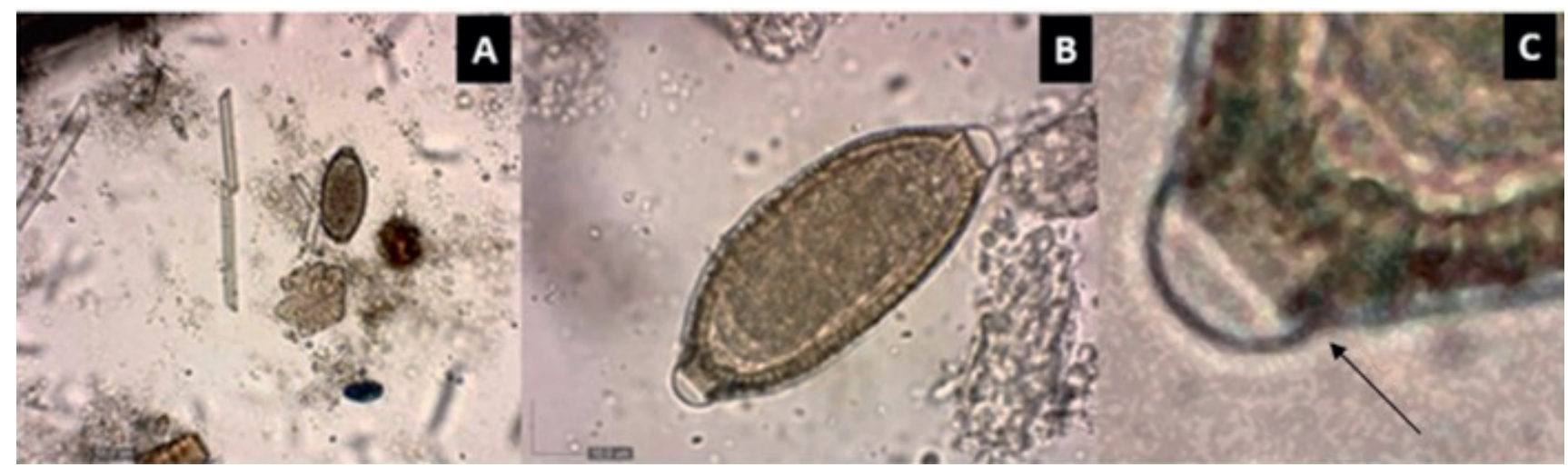

Fig. 2. Coprology examination, light microscopy. A) Eggs of $C$. aerophila (100x magnification); B) Egg of $C$. aerophila (400x magnification); C) Egg polar plugs of $C$. aerophila (1000x magnification). Missing thickening at the base of the bipolar plug (arrow). 
Table 1. Prevalence of endoparasites diagnosed in the feces of examined cats

$\mathrm{N}=155$ (number of cats tested); $\mathrm{N}^{\circ}=$ case number of infection; $\%=$ infection prevalence rate;

\begin{tabular}{lcccc}
\hline \multirow{2}{*}{ ENDOPARASITES } & \multicolumn{2}{c}{ Total number of cats tested } & \multicolumn{2}{c}{ In Monoinfection* } \\
& $\mathrm{N}^{*}$ & $\mathrm{~N} \%$ & $\mathrm{~N}^{\circ}$ & $\mathrm{N} \%$ \\
\hline Toxocara mystax & 29 & 18.71 & 13 & 8.39 \\
Capillaria aerophila & 23 & 14.84 & 16 & 10.32 \\
Isospora spp. & 17 & 10.97 & 6 & 3.87 \\
Ancylostomatidae & 12 & 7.74 & 5 & 3.22 \\
Dipylidium caninum & 5 & 3.22 & 2 & 1.29 \\
Toxascaris leonina & 3 & 1.93 & 3 & 1.93 \\
\hline
\end{tabular}

TOTAL: (67 positive cats of endoparasites) N\% 43,22 *(45 positive cats with monoinfection) N\% 29,03

by coprological examination. The owners were referred to the deworming protocol and were introduced to its importance and currently available preparations on the local market. Twenty-one days after the first treatment, control coprology examinations of cats were performed, and in those that were still positive, the treatment was repeated (for the cats staying mostly outside).

\section{Ethical Approval and/or Informed Consent for research}

Research showing standard clinical/laboratory practices or the advancement of standard practices.

\section{Results}

Parasitological examination

By parasitological examination of 155 cats, we found 23 that were positive for $C$. aerophila, while 44 were positive for other endoparasites (Table 1 and 2). In one cat, the diagnosis was confirmed by coprological examination and targeted partial necropsy, and in the others 22 cats by coprological examination. Parasitological examination of 55 cats with registered respiratory symptoms developmental forms of $C$. aerophila were diagnosed in 23 individuals (eggs in 23 cats and adult parasites in 1 cat). Adult stages of $C$. aerophila were detected in the trachea and large bronchi during

Table 2. Prevalence of mixed endoparasites infections diagnosed in the feces of examined cats $\mathrm{N}=155$ (total number of cats tested); $\mathrm{N}=$ case number of infection; $\%=$ rate in coinfection;

\begin{tabular}{|c|c|c|c|c|c|}
\hline ENDOPARASITES & $\mathrm{N}^{\circ}$ & $\mathrm{N} \%$ & In Double infections & $\mathrm{N}^{\circ}$ & $\mathrm{N} \%$ \\
\hline Toxocara mystax & 16 & 1032 & Toxocara mystax & 4 & 258 \\
\hline & & & $\begin{array}{l}\text { Capillaria aerophila } \\
\text { Isospora spp. }\end{array}$ & 7 & \\
\hline Capillaria aerophila & 7 & 4.52 & Capillaria aerophila & 3 & 1.93 \\
\hline Isospora spp. & 11 & 7.10 & $\begin{array}{l}\text { Isospora spp. } \\
\text { Toxocara mystax }\end{array}$ & 5 & 3.22 \\
\hline Ancylostomatidae & 7 & 4.51 & $\begin{array}{l}\text { Isospora spp. } \\
\text { Ancylostomatidae }\end{array}$ & 3 & 1.93 \\
\hline Dipylidium caninum & 3 & 1.93 & $\begin{array}{l}\text { Toxocara mystax } \\
\text { Ancylostomatidae }\end{array}$ & 4 & 2.58 \\
\hline Toxascaris leonina & l & 1 & $\begin{array}{l}\text { Toxocara mystax } \\
\text { Dipylidium caninum }\end{array}$ & 3 & 1.93 \\
\hline
\end{tabular}

TOTAL: (22 positive cats of double infections) N\% 14.19 


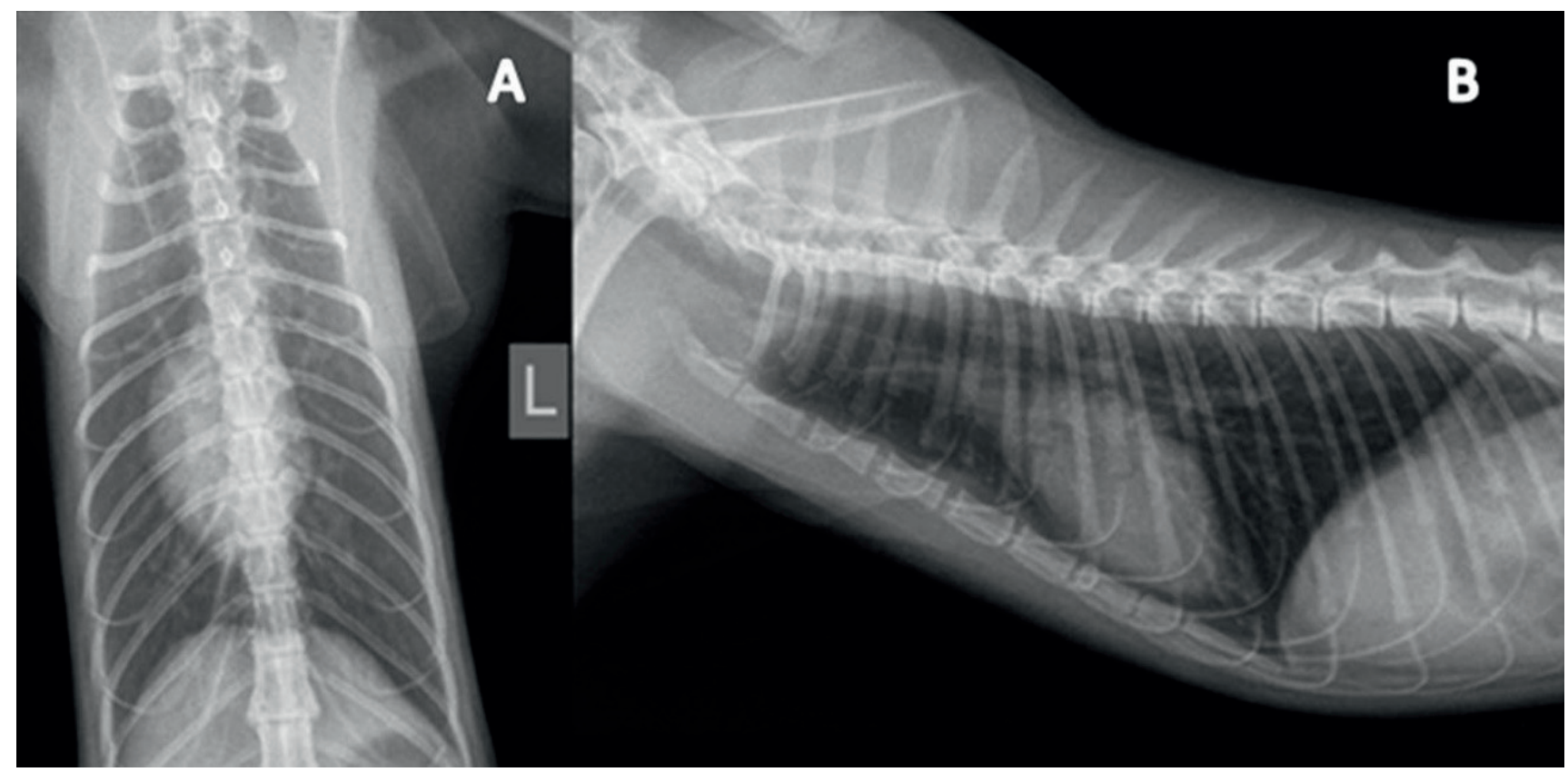

Fig. 3. (A) ventrodorsal and (B) right lateral thoracic X-rays of a two-year-old male cat with Capillaria aerophila infection. A complex lung pattern is visible across the pulmonary fields, characterized by bronchial and alveolar changes and mild reticular interstitial pattern, with the symptoms of the respiratory signs due to; tachypnoea, dyspnoea with abdominal breathing, and end-inspiratory crackles upon auscultation.

necropsy of this cat (Fig. 1A). The eggs of the parasite were identified by the examination of the tracheal washing sample from the deceased cat (Fig. 1B) and in the feces of this and all other cats (Fig. 2A, 2B, and 2C).

Parasitological examination of the feces enabled the detection of $44(28.38 \%)$ positive cats for endoparasites other than C. aerophila. The identified gastrointestinal parasites were Isospora spp. oocysts, T. mystax, T. leonina, Ancylostomatidae eggs, and D. caninum proglottids. The total prevalence of endoparasitic infections was $43.22 \%$ (67/155), with the prevalence of single and mixed infections reaching $29.03 \%$ (45/155) and $14.19 \%$ (22/155), respectively. The highest prevalence of single infection was recorded for Toxocara mystax infection (18.71\%) while the most frequent mixte infections were with Isospora spp and T. mystax (3.22 \%). Mixed infections with $C$. aerophila and Isospora spp were found in $1.93 \%$ (3/155) and with C. aerophila and T. mystax in $2.58 \%$ (4/155) (Table 1 and 2).

\section{Modifications of the physical examination}

Among the 155 cats included in the study, 55 (35.48 \%) displayed respiratory signs on physical examination including tachypnea (75- 80 inspirations per minute) and cough that was usually dry and chronic but occasionally evolved into wet and productive, especially in the presence of secondary bacterial infection. Other abnormalities on physical examination of the 55 cats included tachycardia (sometimes over 200 beats per minute) and fever with a body temperature up to $40^{\circ} \mathrm{C}$ recorded. (Table 3 ).

The prevalence of $C$. aerophila infection detected by parasitologi- cal examination of the feces was $14.84 \%$ and $41.81 \%$ in the total population studied (155 cats) and the cats displaying respiratory signs (55 cats), respectively.

All cats positive for $C$. aerophila belonged to the group of cats with respiratory signs at physical examination. In $90.9 \%$ (50/55) of cats, clinical signs were moderate, which was determined by low $(1-10 \mathrm{epc})$ or medium (11 - $49 \mathrm{epc})$ intensity infections. No statistical analysis has been performed to determine if there is a positive relationship between these two parameters. In this group, one cat $(1.81 \%)$ was presented in a serious clinical condition with severe cyanosis and dyspnea. Unfortunately, the animal died after placing him under oxygen in a respiratory box. The severe $C$. aerophila infection ( $\geq 50 \mathrm{epc}$ ) detected in this cat led to airway obstruction and collapse.

Thoracic auscultation revealed difficult breathing and bilateral crackles. Also, increased respiratory sounds were detected during tracheal auscultation and increased sensitivity of tracheal sensitivity upon artificial cough induction.

In all 22 cats which were treated and survived, a weight loss was reported.

\section{Blood count results}

Bacterial complications are one of the characteristics of parasitic infections, so Table 1 was formed to show only basic hematological results as (WBC), (Er), and (Eo). Leucocytes were between 5.00 to $23.00 \times 10^{9} / \mathrm{L}$, erythrocytes, between $4.5-9.5 \times 10^{12} \mathrm{~g} /$ and the eosinophils $2-6 \%$. Referent values and the results are in (Table 3). 


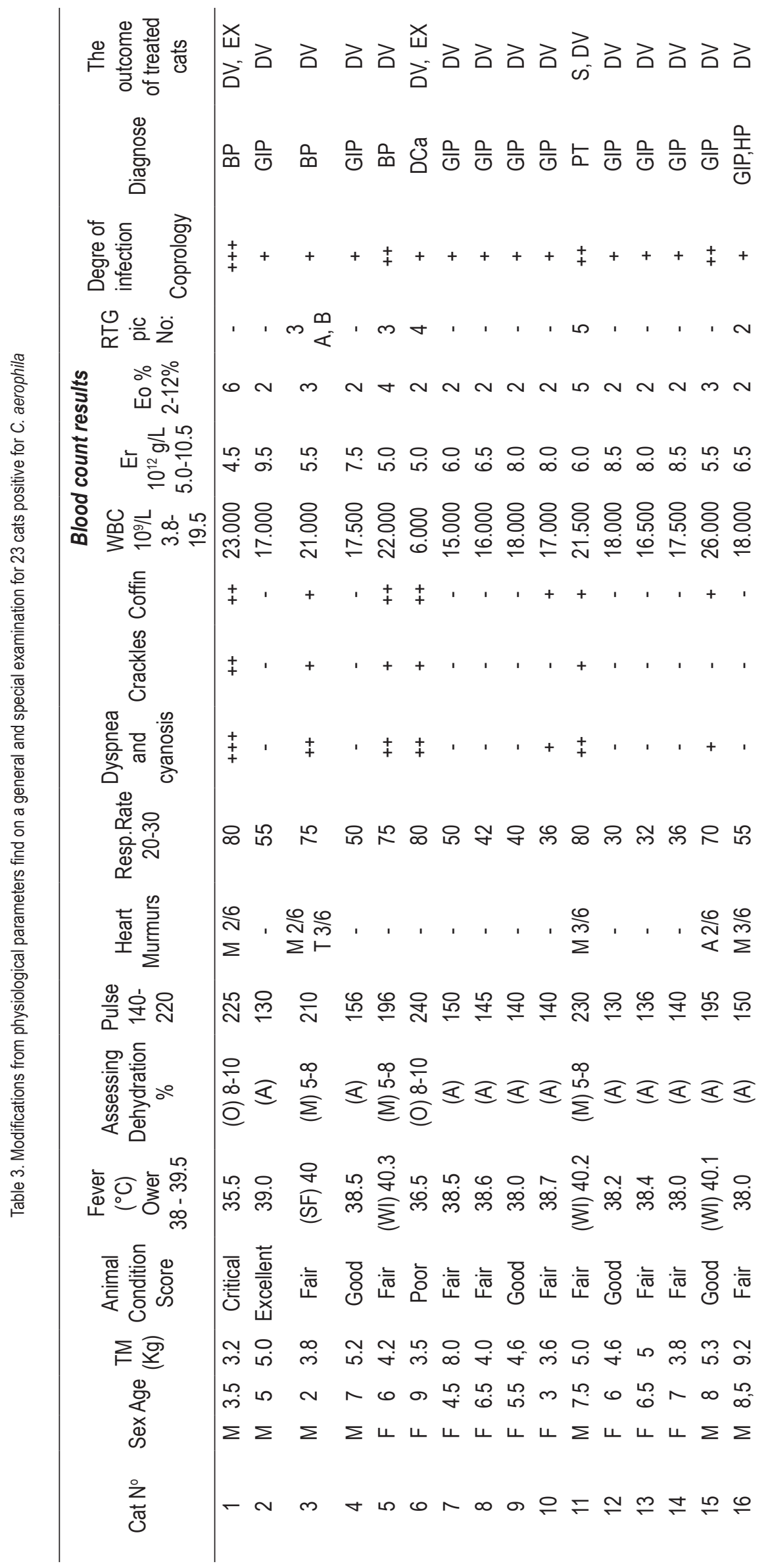




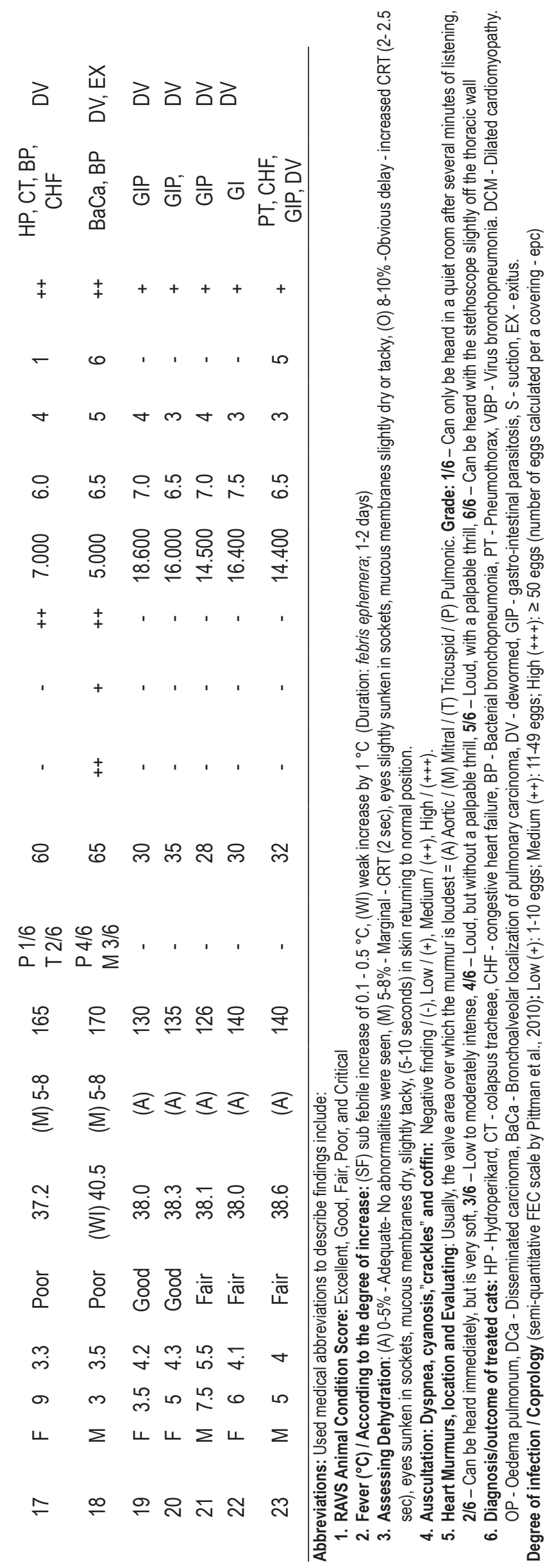




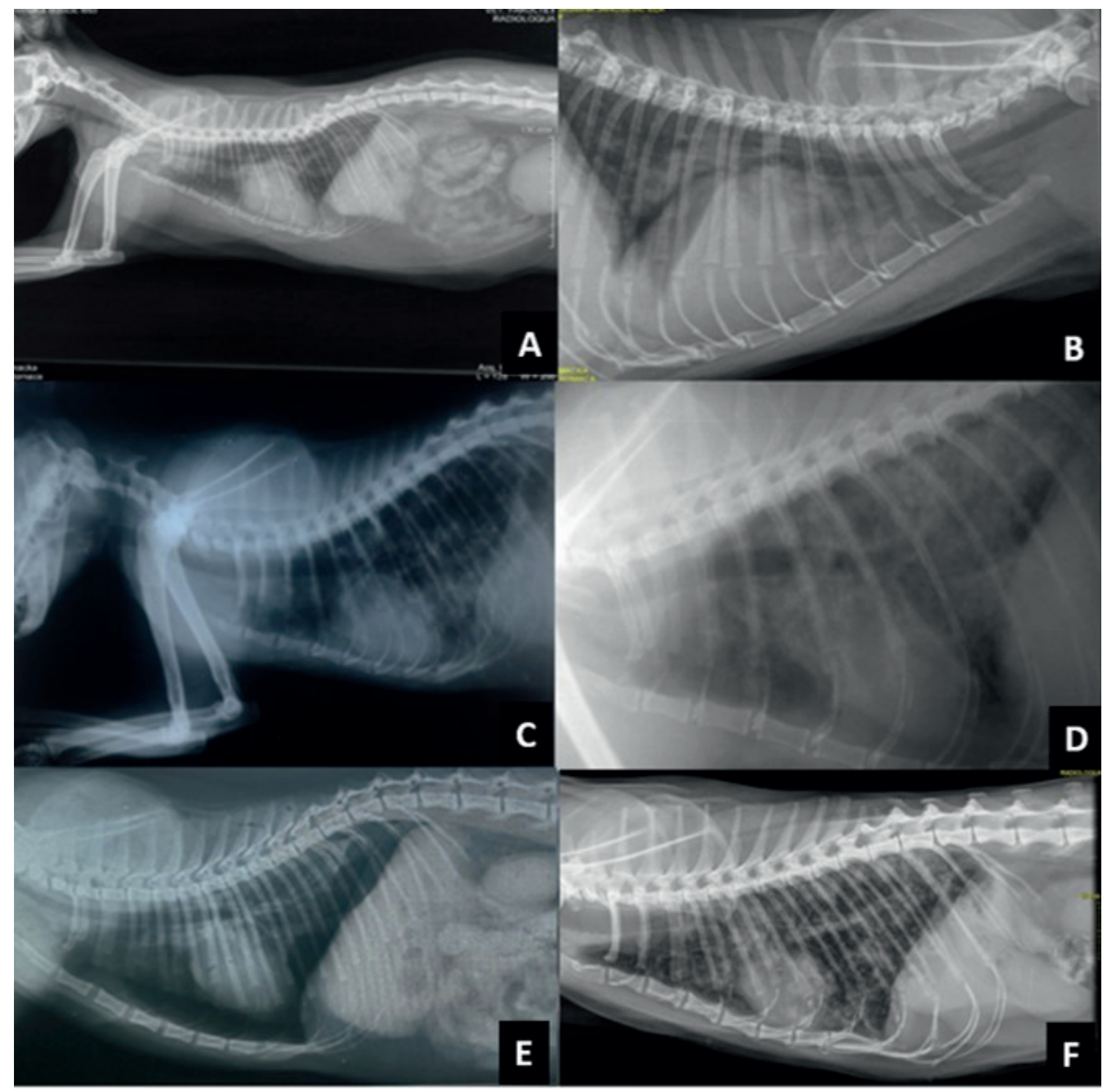

Fig. 4 (A, C, D, E, and F) right lateral thoracic and (B) left lateral thoracic X-rays of the cats with Capillaria aerophila infection.

(A) Right lateral thoracic X-ray a 9 year - old female infected with $C$. aerophila. A complex lung pattern is visible across the pulmonary fields, characterized by bronchial and alveolar changes and mild reticular interstitial pattern and there is an enlargement of the cardiac silhouette with collapses tracheae and ascites.

(B) Left lateral thoracic X-ray an 8,5 year - old male infected with C. aerophila. An oedema pulmonum is present and there is a large enlargement of the cardiac silhouette due to the dilated cardiomyopathy with hydropericardium present with bronchial wall thickening and increased interstitial opacity.

(C) Right lateral thoracic X-ray a 6 year - old female infected with C. aerophila. Bacterial bronchopneumonia with complex lung pattern, characterized by bronchial and alveolar changes and emphysema and atelectasis of the diaphragmatic lobes.

(D) Right lateral thoracic X-ray a 9 year - old female infected with C. aerophila. The virus caused bronchopneumonia with secondary bacterial complications and complex lung pattern, characterized by bronchial and alveolar changes with atelectasis of caudal pulmonary lobes and increased interstitial opacity.

(E) Right lateral thoracic X-ray a 7,5 year -old male infected with C. aerophila. Bacterial bronchopneumonia complicated with pneumothorax and pulmonary hypertension - there is an enlargement of the pulmonary artery of the caudal lobar pulmonary artery.

(F) Right lateral thoracic X-ray a 7,5 year -old male infected with C. aerophila. Bronchoalveolar localization of Ca with oedema pulmonum characterized by bronchial and alveolar changes and very difficult respiratory signs due to; tachypnoea, dyspnoea with abdominal breathing, and end-inspiratory crackles upon auscultation. 
Thoracic radiography results

X-rays of the cats with Capillaria aerophila infection have a typical mild lung pattern across the pulmonary fields and is characterized by mild bronchial and alveolar changes and a mild reticular interstitial picture (Fig. 3) We present radiograms of the ventrodorsal and right lateral thoracic X-rays of 7 cats with $C$. aerophila infection. Four of them had bronchopneumonia with a mild reticular interstitial pattern or with complex lung pattern which was visible across the pulmonary fields, characterized by bronchial and alveolar changes and increased interstitial opacity due to bacterial bronchopneumonia, or viral bronchopneumonia complicated with the secondary bacterial infection, pneumothorax, edema pulmonum, bronchial wall thickening, emphysema, atelectasis, tracheal collapse, an enlargement of the pulmonary artery and pulmonary hypertension. Those changes were followed by respiratory clinical signs due to: tachypnea, dyspnea, abdominal breathing, and end-inspiratory crackles upon auscultation (Fig. 4).

Four cats $(7.27 \%$; 4/55) had severe mixed dyspnea upon auscultation, with the hematology panel indicating eosinophilia and bronchitis on chest x-ray (Fig. 3A, 3B), based on which eosinophilic granulomatous pneumonia was suspected. In $9.1 \%(5 / 55)$ of cats, dyspnea accompanied by wheezing and crepitations were detected during pulmonary auscultation and were suspected to be due to bronchopneumonia. Hematology panel of these animals showed leukocytosis and eosinophilia. Infection of the lower portions of the airways in diseased cats was accompanied by hyperthermia in $21,7 \%(5 / 23)$ of cats.

\section{Cytological evaluation of the tracheal lavage of one dead cat} In most cats with respiratory symptoms, bronchial lavage reveals the presence of cellular exudate, foam, and mucus, while in some cats adult $C$. aerophila stages were present in the lumen of the bronchi. Cytology of the bronchoalveolar fluid can demonstrate moderate cellular density, large amounts of degenerated neutrophils (>90\%), and intracellular bacteria (Coccobacilli), suggesting the presence of suppurative bronchitis. There were no deviations from physiological parameters in the performed cytological analyzes of one dead cat.

Domestic cats brought by the owners had constant access to the open space. For 55 cats, we found a history of respiratory symptoms lasting from 2 weeks to 4 months. All the examined cats had been previously treated in some private veterinary clinic, even for as long as several weeks, for various respiratory conditions: snoring, dysphonia, and initially nonproductive cough, which a short time after had usually turned into a productive cough. During the treatment, cats were treated with corticosteroids, one or several antibiotics, including enrofloxacin, doxycyclin, and cephalosporins, and some of them were also on nebulization therapy. In general, the therapy did not produce improvements.

\section{Discussion}

In carnivores, $C$. aerophila infection usually causes chronic bronchitis (Traversa et al., 2010). However, it can follow different clinical courses, from mild subclinical infection to life-threatening acute respiratory distress (Traversa et al., 2010).

Rehbein et al. (2014) have described a prevalence of $6.6 \%$ of Capillaria spp. eggs in the the feces of cats in seven European countries (Albania - 31,6\%, Austria - 3,8 \%, Bulgaria - 4,3\%, Germany - 1,6 \%, Hungary - 5,0 \%, Latvia - 4,1\%, Lithuania - 2,6 \%). The total number of infection varied among the regions probably because of differences in the living behavior of the studied cats (rural, suburban, or urban areas).

As the most common helminths, gastrointestinal parasites have been described in cats worldwide: ascarids (Toxocara cati and with a significantly lower prevalence of Toxascaris leonina), hookworms (mainly Ancylostoma tubaeforme and depending on climate, occasionally Uncinaria stenocephala), cestodes from family Dilepididae and Taenidae (predominantly Taenia taeniaeformis, and less frequently Echinococcus multilocularis in endemic areas) (Rehbein et al., 2014).

In this study of gastrointestinal parasitosis, the highest prevalence of toxocariasis (18.83\%) was diagnosed, followed by Isospora spp (10.97 \%) and ancylostomatids (7.74 \%). Of the mixed infections, only double infections were identified. The most common infection was Isospora spp. and T. mystax (3.22\%), and an identical prevalence $(2.58 \%)$ of coinfection of this ascarid with $\mathrm{C}$. aerophila and ancylostomatids were found. The factors such as cat category (e.g., stray cats, cats from animal shelters, pets kept under controlled conditions), habitat (urban or rural) or access to open spaces can have a significant impact on the variation of prevalence of these endoparasitoses (Mircean et al., 2010; Capari et al., 2013). The first studies of respiratory capillariosis in cats in Serbia were conducted in the area of Belgrade in the period $2003-2007$ when the prevalence of $C$. aerophila was determined to be $8.03 \%$ (llić et al., 2009). In the last decade, the prevalence of this nematode in cats in Belgrade has almost doubled. The established growth trend can be attributed to the increase in the number of foxes as a reservoir of infection for pets (Traversa \& Di Cesare, 2016). This claim is supported by the results of research, according to which an extremely high prevalence of $C$. aerophila was found in foxes in Serbia (Lalošević et al., 2013; llić et al., 2016).

Several studies from different countries have confirmed that in the past two decades the number of cases of respiratory capillariasis has grown both in cats and humans (Barrs et al., 2000; Di Cesare et al., 2012; Cross, 1998; Lalošević et al., 2008). Human infections have been described in Ukraine, Russia, France, Morocco, Iran (Di Cesare et al., 2012), and Serbia as well (Lalošević et al., 2008). Some recent molecular-based studies have shown that different 
haplotypes of $C$. aerophila may circulate between domestic and wild carnivores (Di Cesare et al., 2012). Indeed, genetic studies demonstrated that some $C$. aerophila haplotypes may infect both pet and wild animals from the same locations suggesting that wild animals may have an impact on the transmission to and the propagation of respiratory capillariosis in the feline population (Traversa \& Di Cesare, 2016). In Europe, fifteen different haplotypes have been identified, out of which five are identical between pet and wild animals in Italy (Di Cesare et al., 2014). Three genetic subpopulations infecting cats and foxes were identified in Serbia (haplotype I and II) and one each in Romania (haplotype I) and Portugal (haplotype VII) (Di Cesare et al., 2014).

Literature data also suggests that cats can be infected with the nematodes from the Trichuris genus ( $T$. felis, $T$. campanula, and T. serrata). Although these species are very rarely diagnosed in cats and only in limited geographical areas (Traversa et al., 2010; Traversa, 2011), the finding of their eggs in the feces additionally complicates the interpretation of coprology results and precise diagnosis (Traversa \& Di Cesare, 2016; Giannelli et al., 2017).

The predominant clinical signs associated with respiratory capillarisosis are productive cough accompanied by mucopurulent nasal discharge, tachypnea, dyspnea with evident abdominal breathing, and end-inspiration crackling during auscultation. In more severe cases, respiratory failure leads to mucosal cyanosis and respiratory acidosis (Traversa et al., 2012). In $14.84 \%$ of the studied cats, increased broncho-vesicular respiratory sounds, sneezing, wheezing and dry cough were the most frequent clinical signs detected. These clinical findings are the result of $C$. aerophila adult worms which are capable of inducing lesions in the trachea and lung parenchyma. In a few cases, the cough became productive probably because of a more advanced disease phase associated with secondary bacterial bronchopneumonia. Fever was the consequence of secondary bacterial bronchopneumonia.

Furthermore, the achievement of an accurate diagnosis is further complicated because some cats infected with respiratory parasites can display clinical improvement after unspecific treatment including corticosteroids and bronchodilators (Traversa \& Di Cesare, 2016). This apparent improvement can delay the definitive diagnosis for several weeks (Traversa \& Di Cesare, 2016).

The differential diagnosis may include all diseases causing upper and/or lower respiratory signs including other parasitic infections (dirofilariasis, pulmonary toxoplasmosis, aelurostrongylosis, troglostrongylosis) but also tracheobronchitis, tracheal stenosis, pneumonia (of bacterial, viral or fungal etiology), airway obstructions caused by foreign bodies, nasopharyngeal polyps, tumors, pulmonary granulomatosis, allergies, and chronic bronchial diseases affecting cats (asthma) (Spada et al., 2013; llić et al., 2015). All the before mentioned diseases are not characterized by pathognomonic symptoms which complicates the clinical diagnosis.

Complications associated with a fatal outcome in infected animals are interstitial emphysema, lung edema, and secondary bacterial infections (Traversa et al. 2012). In some cases, these infec- tions may be complicated by pleural effusions or pneumothorax (Traversa et al., 2009). An additional complication is an absence or the non-pathognomonic abnormalities detect on thoracic radiographs (Traversa et al. 2012) The most common finding is an alveolar lung pattern, possibly associated with the bronchial and interstitial pattern, with bronchial wall thickening and reduced interstitial transparency (Traversa et al. 2012). In chronic or mixed infections, right-side cardiomegaly may develop, associated with eccentric hypertrophy, occurring secondary to pulmonary hypertension. This condition is the consequence of severe bronchopneumonia caused by a secondary bacterial infection or mixed infection with A. abstrusus or Dirofilaria immitis (Dirven et al., 2012).

Secondary bacterial infections contribute to the severity of parasitic infections of the lungs; that is the reason why broad-spectrum antibiotics combined with corticosteroids should always be administered (at anti-inflammatory doses) to all cats with bronchopneumonia symptoms (Foster, 2004). Pleural effusion and pneumothorax require immediate thoracocentesis (pleural tap) (Pechman, 1984). The care of a cat with respiratory failure should include the management in an intensive care unit with mandatory use of oxygen therapy and nebulization (Foster, 2004).

All the cats included in this study reached a complete improvement (absence of clinical signs and negative coprology results) after treatment with fenbendazole. However, in some of these cats, clinical signs were present for even up to six weeks after anthelminthic treatment, as shown by positive coprology results for $C$. aerophila. This could be explained by either reinfection due to living conditions (households with many cats and free access to open spaces) or by a partial response to fenbendazole treatment. Several protocols have been reported in the literature for the treatment of respiratory capillariosis in cats, such as the combinations of fenbendazole paste, milbemycin-oxime/praziquantel, various spot-on formulations, abamectin, ivermectin, and levamisole (Brianti et al., 2013; Traversa \& Di Cesare, 2013). Oral administration of fenbendazole with different doses and duration of treatment has been suggested by several authors (from $20 \mathrm{mg} / \mathrm{kg}$ in 5 days to 50 $\mathrm{mg} / \mathrm{kg}$ in 15 days) as effective treatment (Grandi et al., 2005). Although positive results have been reported with ivermectin, there is a prevailing opinion that these agents should not be used in cats, especially in kittens, due to toxicity concerns (Brianti et al., 2013; Traversa \& Di Cesare, 2013). In fieldwork, individual administration of the formulation imidacloprid $10 \%$ / moxidectin $1 \%$ in naturally infected cats has been reported to be safe and effective. To improve clinical signs, supportive therapy is recommended to help respiratory function, eliminate secondary infection, and stimulate the appetite of affected cats (Gianelli et al., 2014).

Environmental changes resulting from global warming in addition to oral vaccination against rabies have significantly increased the population of wild carnivores, especially foxes (llić et al., 2016a). The population of foxes has to be considered as a constant reservoir of infection for domestic carnivores in suburban areas. therefore, data on the way of living and the territory of owned cats are 
very important to collect when taking anamnesis. Similarly, canine and feline stray populations have increased in both urban and suburban environments in Serbia (Đurić et al., 2011; Lažetić et al., 2012). Consequently, the increase in both populations of will and stray carnivores has contributed to significantly raise the population of possible reservoirs for pets, creating favorable conditions for the constant maintenance and spread of zoonotic parasites (Obrenovic et al., 2003; Nikolić et al., 2008; Ilić et al., 2017; Ilić et al., 2017a) including C. aerophila.

Because of the direct life cycle and zoonotic potential of $C$. aerophila, sanitary measures are necessary to control the disease, especially in living environments with larger groups of animals (Brianti et al., 2012; Gianelli et al., 2014; Brianeri et al., 2014).

\section{Conclusion}

Considering the zoonotic potential of $C$. aerophila and the spreading tendency of parasitic diseases caused by nematodes, more effort should be managed to achieve an accurate diagnosis of the causal organism. This study stressed out the importance of including parasitic diseases in the differential diagnosis of respiratory conditions in cats. Although allergic bronchitis is usually considered the most frequent cause of chronic cough in cats, it is recommended to delay the steroid therapy until a potential infection is excluded.

In humans, the disease is characterized by a non-specific clinical picture and is usually detected accidentally, which is the reason why prevention measures are essential in the fight against this parasitosis of cats. Finally, this study contributes to a better understanding of the epidemiology of respiratory capillariosis in the city of Belgrade and highlights the possibility of human infection due to the close contact between infected pet cats and their owners.

\section{Conflict of Interest}

The authors declare that they have no conflict of interest.

\section{Acknowledgments}

The study was supported by the Ministry of Education, Science and Technological Development of the Republic of Serbia (Contract number 451-03-68/2020-14/200143). Special thanks to Prof dr Nikola Krstić, Head of the Department of Radiology and Radiation Hygiene, Faculty of Veterinary medicine University of Belgrade, for his support.

\section{References}

Anderson, R.C., Chabaud, A.G., Willmott, S. (2009): Keys to the Nematode Parasites of Vertebrates. Archival Volume, Wallingford, Oxfordshire, UK, CABI Publishing, 436 pp.

Barrs, V.R., Martin, P., Nicoll, R.G., Beatty, J.A., Malik, R. (2000):
Pulmonary cryptococcosis and Capillaria aerophila infection in an FIV-positive cat. Aust. Vet. J., 78 (3): 154 - 158. DOI: 10.1111/ j.1751-0813.2000.tb10581.x

Bowman, D.D., Hendrix, C.M., Lindsay, D.S., BarR, S.C. (2008): Feline Clinical Parasitology. 2nd Edition, Ames, IA, lowa State University Press, Blackwell Science Company, 339 pp.

Brianeri, E., Giannetto, S., Dantas-Torres, F., Otranto, D. (2014): Lungworms of the genus Trogostrongylus (Strongylida: Crenosomatidae): neglected parasites of domestic cats. Vet. Parasitol., 202 (3 - 4): 104 - 115. DOI: 10.1016/j.vetpar.2014.01.019

Brianti, E., Gaglio, G., Giannetto, S., Annoscia, G., Latrofa, S.M., Dantas-Torres, F., Traversa, D., Otranto, D. (2012): Trogostrongylus brevior and Trogostrongylus subcrenatus (Strongylida: Crenosomatidae) as agents of broncho-pulmonary infestation in domestic cats. Parasit. Vectors, 5: 178. DOI: 10.1186/1756-3305-5-178 Brianti, E., Gaglio, G., Napoli, E. (2013): Evidence for direct transmission of the cat lungworm Trogostrongylus brevior (Strongylida: Crenosomatidae). Parasitol., 140: 821 - 824. DOI: 10.1177/1098612X15623113

Capári, B., Hamel, D., Visser, M., Winter, R., Pfister, K., RehBEIN, S. (2013): Parasitic infections of domestic cats, Felis catus, in western Hungary. Vet. Parasitol., 192 (1 - 3): 33 - 42. DOl: 10.1016/j.vetpar.2012.11.011

Cross, J.H. (1998): Capillariosis. In: Palmer, S.R., Soulsby, L., Simpson, D.I.H. (Eds) Zoonoses. Biology, Clinical Practice, and Public Health Control. Oxford, UK, Oxford University Press, pp. 789 - 802 Crum, J.M., Nettles, V.F., Davidson, W.R. (1978): Studies on endoparasites of the black bear (Virsus americanus) in the southeastern United States, J. Wild. Dis., 14 (2): 178 - 186. DOI: 10.7589/00903558-14.2.178

Č́abrilo, O.B., Simin, V., Miluević, M., Čabrilo, B., Mijatović, D., LALOŠEVIĆ, D. (2018): Respiratory and cardiopulmonary nematode species of foxes and jackals in Serbia. Helminthol., 55 (3): 213-221. DOI: 10.2478/helm-2018-0019

Di Cesare, A., Castagna, G., Otranto, D., Meloni, S., Milillo, P., Latrofa, S.M., Paoletti, B., Bartoliniet, R., Otranto, D. (2012): Molecular detection of Capillaria aerophila, an agent of canine and feline pulmonary capillariosis. J. Clin. Microbiol., 50: 1958 - 1963. DOI: 10.1128/JCM.00103-12.

Di Cesare, A., Meloni, S., Milillo, P., Castagna, G., Otranto, D., Paoletti, B., Bartolini, R., Avolio, S., Traversa, D. (2010): Feline and canine cardio-pulmonary nematodes in central and southern Italy. Proceedings of the XXVI SolPa Congress: June $22-25$, 2010; Perugia, Italy, p. 307

Di Cesare, A., Otranto, D., Latrofa, S.M., Veronesi, F., Perrucci, S., Lalosevic, D., Gherman, M, C, Traversa, D. (2014): Genetic variability of Eucoleus aerophilus from domestic and wild hosts. Res. Vet. Sci., 96: 512 - 515. DOI: 10.1016/j.rvsc.2014.03.018

Dirven, M., Szatmári, V., Van Den Ingh, T., NiJsse, R. (2012): Reversible pulmonary hypertension associated with lungworm infection in a young cat. J. Vet. Cardiol., 14 (3): 465 - 474. DOI: 10.1016/j.jvc.2012.04.005 
Đurić, B., Ilić, T., Trallović, D., Kulšlı́, Z., Dimitrijević, S. (2011): Parazitske infekcije digestivnog trakta pasa na području Braničevskog okruga. Vet. Glasnik, 65 (3 - 4): 223 - 234. DOI: 10.2298/VETGL1104223D

EcheVerRy, D.M., GiRaldo, M.I., Castaño, J.C. (2012): Prevalencia de helmintos intestinales en gatos domésticos del departamento del Quindío, Colombia. Biomedica, 32: 430 - 436. DOI: 10.7705/ biomedica.v32i3.439

Foster, S.F., Martin, P., Allan, G.S., BarRs, V.R., Malik, R. (2004): Lower respiratory tract infections in cats: 21 cases (1995 - 2000). J. Feline Med. Surg., 6 (3): 167 - 180. DOI: 10.1016/j. jfms.2003.11.006

Gianelli, A., Passantino, G., Ramos, R.A., Lo Presti, G., Lia, R.P., Brianti, E., Dantas-Torres, F., Papadopoulos, E., Otranto, D. (2014): Pathological and histological findings associated with the feline lungworm Trogostrongylus brevior. Vet. Parasitol., 204 (3 - 4): 416 - 419. DOI: 10.1016/j.vetpar.2014.05.020

Giannelli, A., Capelli, G., Joachim, A., Hinney, B., Losson, B., KiRKova, Z., René-Martellet. M., Papadopoulos, E., Farkas, R., Napoli, E., Brianti, E., Tamponi, C., Varcasia, A., Alho, M.A., Madeira De Carvalho, L., Cardoso, L., Maia, C., Mircean, V., Mihalca, D.A., Miró, G., Schnyder, M., Cantacessi, C., Colella, V., Cavalera, A.M., Latrofa, S.M., Annoscia, G., Knaus, M., Halos, L., Beugnet, F., OtRAnTO, D. (2017): Lungworms and gastrointestinal parasites of domestic cats: a European Perspective. Int. J. Parasitol., 47 (9): 517 - 528. DOI: 10.17863/CAM.9600

Gompper, M.E., Goodman, R.M., Kays, R.W., Ray, J.C., Fiorello, C.V., WADE, S.E. (2003): A survey of parasites of coyotes (Canis latrans) in New York-based on fecal analysis, J. Wild. Dis., 39 (3): 712 - 717. DOI: 10.7589/0090-3558-39.3.712

Grandi, G., Calvi, L.E., Venco, L., Paratici, C., Genchl, C., Memmi, D., KRAmer, L.H. (2005): Aelurostrongylus abstrusus (cat lungworm) infection in five cats from Italy. Vet. Parasitol., 134 (1 - 2): 177 - 182. DOI: 10.1016/j.vetpar.2005.06.015

HARALAMPIDES, S.T. (1978): Contribution to the study of cat's parasites and their public health importance. Hellenike Kteniatrike, 21: $117-119$.

Ilić, T., Becskel, Zs., Tasić, A., Stepanović, P., Radisavluević, K., Đurić, B., DimitrIJević, S. (2016): Red foxes (Vulpes vulpes) as reservoirs of respiratory capillariosis in Serbia. J. Vet. Res., 60, 153 - 157. DOI: 10.1515/jvetres-2016-0022

Ilić, T., Mandić, M., Stepanović, P., DimitriJević, S. (2015): Respiratorna kapilarioza pasa i mačaka - klinički, parazitološki i epidemiološki značaj. Vet. Glasnik, 69 (5 - 6): 417 - 428. DOI: 10.2298/ VETGL1506417I

licí, T., Stepanović, P., Mandić, M., Obrenović, S., Dimitrijević, S. (2017): The cardiopulmonary metastrongylidosis of dogs and cats contribution to diagnose. Vet. Glasnik, 71 (2): 69 - 86. DOI: 10.2298/VETGL170310010I

ILIĆ, T., DimitriJević, S., Mitrović, S., Džamić, A., Đurić, B. (2009): Capillariosis - opportunistic zoonosis. XIV Annual Conference of veterinarians of the Republic of Srpska (Bosnia and Herzegovina),
Book of abstracts: June 03 - 06, 2009; Jahorina, Bosnia and Herzegovina, p. 78.

Ilić, T., Kulišić, Z., Antić, N., Radisavluević, K., Dimitrijević, S. (2017a): Prevalence of zoonotic intestinal helminths in pet dogs and cats in the Belgrade area. J. Appl. Anim. Res., 45 (1): 204 - 208. DOI:10.1080/09712119.2016.1141779

llić, T., Becskel, Z., Petrović, T., Polaček, V., Ristić, B., Milić, S., Stepanović, P., Radisavluević, K., DimitriJević, S. (2016a): Endoparasitic fauna of red foxes (Vulpes vulpes), and golden jackals (Canis aureus) in Serbia. Acta Parasitol., 61 (2): 389 - 396. DOI: 10.1515/ap-2016-0051.

Elhamiani Khatat, S., Rosenberg, D., Benchekrou, G., Polack, B. (2016): Lungworm Eucoleus aerophilus (Capillaria aerophila) infection in a feline immunodeficiency virus-positive cat in France. J. Feline Med. Surg., 2 (1): 2055116916651649. DOI: 10.1177/2055116916651649

Knaus, M., Rapti, D., Shukullari, E., Kusi, I., Postoli, R., Xhaxhiu, D., Silaghi, C., Hamel, D., Visser, M., Winter, R., Rehbein, S. (2014): Characterisation of ecto- and endoparasites in domestic cats from Tirana, Albania. Parasitol. Res., 113 (9): 3361 - 3371. DOI:10.1007/s00436-014-3999-1

Knaus, M., Shukullarl, E., Rapti, D., Rehbein, S. (2015): Efficacy of Broadline against Capillaria aerophila lungworm infection in cats. Parasitol. Res., 114 (5): 1971 - 1975. DOI: 10.1007/s00436-0154386-2.

Kochanovski, M., Dabrowska, J., Karamon, J., Cencek, T., Osinski, Z. (2013): Analysis of the accuracy and precision of the McMaster method in the detection of the eggs of Toxocara and Trichuris species (Nematoda) in dog feces. Folia Parasitol., 60 (3): 264 - 272. DOI: $10.14411 / f p .2013 .030$.

Kohart, N.A., Boes, K.M., Sponenberg, D.P., KIsS, C. (2014): What is your diagnosis? Lung impression smear from a stray kitten. Vet. Clin. Pathol., 43 (1): 113 - 114. DOI: 10.1111/vcp.12103.

Krone, O., Guminsky, O., Meinig, H., Herrmann, M., Trinzen, M., WIBELT, G. (2008): Endoparasite spectrum of wild cats (Felis silvestris Schreber, 1777) and domestic cats (Felis catus L) from the Eifel, Pfalz region and Saarland, Germany. Eur. J. Wildl. Res., 54 (1): 95 - 100. DOI: 10.1007/s10344-007-0116-0

Lalosević, D., Lalosević, V., Klem, I., Stanojev-Jovanović, D., Pozio, E. (2008): Pulmonary capillariasis miming bronchial carcinoma. Am. J. Trop. Med. Hyg., 78 (1): $14-16$.

Lalošević, V., Lalošević, D., Čapo, I., Simin, V., Galfi, A., Traversa, D. (2013): High infection rate of zoonotic Eucoleus aerophilus infection in foxes from Serbia. Parasite, 20 (3): 1 - 5. DOI:10.1051/ parasite/2012003

Langham, N.P.E., Charleston, W.A.G. (1990): An investigation of the potential for spread of Sarcocystis spp. an other parasites by feral cats. New Zeal. J. Agr. Res., 33: 429 - 435. DOI: 10.1080/00288233.1990.10428439

LAŽETIĆ, V., ILIĆ, T., ILIĆ, V., DIMITRIJEVIĆ, S. (2012): Parazitske bolesti mačaka na beogradskom području sa posebnim osvrtom na zoonoze. Arhiv Vet. Med., 5 (2): 53 - 66. 
Madeira De Carvalho, L.M., Pereira Da Fonseca, L.M., Gomes, L., MEIRELES, J.M. (2009): Lungworms in domestic and wild carnivores in Portugal: rare parasites or rarely diagnosed? Proceedings of the Bayer Angiostrongylosis Forum, 19th Annual Congress of the European College of Veterinary Internal Medicine - Companion Animals: September 09, Porto, Portugal, p. 28.

Matoyoshi, M., Ameku, Y., Keruma, T., Kinjo, E. (1996): Isolation of Pasteurella dagmatis from an iriomote cat (Felis iriomotensis) with parasitic bronchopneumonia. J. Jap. Vet. Med. Assoc., 49 (12): $879-883$.

MLLSTEIN, T.C., GoldSMID, J.M. (1997): Parasites of feral cats from southern Tasmania and their potential significance. Aust. Vet. J., 75 (3): 218 - 219. DOI: 10.1111/j.1751-0813.1997.tb10072.x

MiRCEAN, V., TITLINCU, A., VAsILE, C. (2010): Prevalence of endoparasites in household cat (Felis catus) populations from Transylvania (Romania) and association with risk factors. Vet. Parasitol., 171: $163-166$.

Nikolić, A., Dimitrijević, S., Katić Radivojević, S., Klun, I., Bobić, B., ĐuRKović-ĐaKović, O. (2008): High prevalence of intestinal zoonotic parasites in dogs from Belgrade, Serbia - short communication. Acta Vet. Hung., 56 (3): 335 -340. DOI: 10.1556/AVet.56.2008.3.7. Obrenović, S., Katić-Radivojević, S., Stanković, B. M., Bacić, D. (2003): Sarcocystiosis in dogs in several regions of Serbia (Article). Acta Vet. Belgrade, 53 (1): 19 - 26. DOI:10.2298/AVB03010190. Paoletti, B., lorio, R., Traversa, D., Di Francesco, C.E., Gentile, L., Angeluccl, S., Amicuccl, C., Bartolini, R., Marangl, M., Di CeSARE, A. (2017): Helminth infections in faecal samples of Apennine wolf (Canis lupus italicus) and Marsican brown bear (Ursus arctos marsicanus) in two protected national parks of central Italy. Ann. Parasitol., 63 (3): 205 - 212. DOI: 10.17420/ap6303.107.

Pechman, R.D. (1984): Newer knowledge of the feline bronchopulmonary disease. Vet. Clin. North Am. Small Anim. Pract., 14: $1007-1019$.

Pence, D.B., Bryant, F.C. (2002): Effect of short - term coyote removal on populations of coyote helminths. J. Wild. Dis., 38 (1): 54 - 67. DOI: 10.7589/0090-3558-38.1.54

Pittman, S.J., Shepherd, G., Thacker, J.B., Myers, H.G. (2010): A modified technique for collecting and processing fecal material for diagnosing intestinal parasites in swine. J. Swine Health Prod., 18 (5): $249-252$.

Rehbein, S., Capári, B., Duscher, G., Keidane, D., Kirkova, Z., Petkevičlus, S., Rapti, D., Wagner, A., Wagner, T., Chester, T., Rosentel, J., Tielemans, E., Visser, M., Winter, R., Kley, K., Knaus, M. (2014): Efficacy against nematode and cestode infections and safety of a novel topical fipronil, (S)-methoprene, eprinomectin and praziquantel combination product in domestic cats under field conditions in Europe. Vet. Parasitol., 202 (1-2): 10 - 17. DOI: 10.1016/j.vetpar.2014.02.032
Schuster, R., Nockler, K., Mix, H. (2001): Helminth findings in indigenous racon dogs Nyctereutes procyonoides. Berl. Munch. Tierarztl. Wochenschr., $114(7-8): 273-276$.

SLoss, M.W., KeMP, R..L, ZAJAC, A.M. (1994): Veterinary Clinical Parasitology. 6th Edition, Ames, IA, lowa State University Press, Wiley-Blackwell, 208 pp.

Spada, E., Proverbio, D., Della Pepa, A., Domenichini, G., Bagnagatti De Giorgl, G.B., Trald, G., Ferro, E. (2013): Prevalence of faecal-borne parasites in colony stray cats in northern Italy. J. Feline Med. Surg., 15: 672 - 677. DOI: 10.1177/1098612X12473467 Sréter, T., Széll, Z., Maruccl, G., Pozio, E., Vorgl, I. (2003): Extraintestinal nematode infections of red foxes (Vulpes vulpes) in Hungary. Vet. Parasitol., 115 (4): 329 - 334. DOI: 10.1016/s03044017(03)00217-6

Thienpoint, D., Vanpariss, O., Hermans, L. (1981): Epidemiology of helminthiases of the cat in Belgium. The prevalence of Ollulanus tricuspis. Rec. Med. Vet. l'Ecole d'Alfort, 157:591 - 595

Traversa, D., DI Cesare, A. (2013): Feline lungworms: what a dilemma. Trends Parasitol., 29 (9): 423 - 430. DOI: 10.1016/j. pt.2013.07.004

Traversa, D., Di Cesare, A., Lia, R.P., Castagna, G., Meloni, S., Heine, J., Strube, K., Milillo, P., Otranto, D., Meckes, O., Schaper, R. (2011): New insights into morphological and biological features of Capillaria aerophila (Trichocephalida, Trichuridae). Parasitol. Res., 109 (suppl. 1): S97-S104. DOI: 10.1007/s00436-011-2406-4 Traversa, D., Di Cesare, A., Milillo, P., lorio, R., Otranto, D. (2009): Infection by Eucoleus aerophilus in dogs and cats: is another extra-intestinal parasitic nematode of pets emerging in Italy? Res. Vet. Sci., 87 (2): 270 - 272. DOI: 10.1016/j.rvsc.2009.02.006 Traversa, D., DI CeSARE, A. (2016): Diagnosis and management of lungworm infections in cats. J. Feline Med. Surg., 18: 7 - 20. DOI: 10.1177/1098612X15623113

TRAVERSA, D. (2011): Are we paying too much attention to cardio-pulmonary nematodes and neglecting old-fashioned worms like Trichuris vulpis? Parasite. Vector., 4 (1): 32 - 43. DOI: 10.1186/1756-3305-4-32

Traversa, D., Di Cesare, A., Conboy, G. (2010): Canine and feline cardiopulmonary parasitic nematodes in Europe: emerging and underestimated. Parasite. Vector., 3 (1): 62 - 84. DOI: 10.1186/1756-3305-3-62

Traversa, D., Di Cesare, A., Castagna, G., Schaper, R., Braun, G., Lohr, B., Pampurini, F., Milıllo, P., Strube, K. (2012): Efficacy and safety of imidacloprid $10 \%$ /moxidectin $1 \%$ spot-on formulation in the treatment of feline infection by Capillaria aerophila. Parasitol. Res., 111 (4): 1793 - 1798. DOI: 10.1007/s00436-012-3025-4

WaAP, H., Gomes, J., Nunes, T. (2014): Parasite communities in stray cat populations from Lisbon, Portugal. J. Helminthol., 88 (4): 389 - 395. DOI: 10.1017/S0022149X1300031X 